\title{
Entre identidades e tendências: 0 ensino de língua estrangeira na escola
}

\author{
ENTRE IDENTIDADES Y TENDENCIAS: LA ENSEÑANZA DE \\ LENGUA EXTRANJERA EN LA ESCUELA
}

Maria Mercedes SEBOLD *

Resumo: O ensino da habilidade de leitura na escola não resolveu o problema do fracasso escolar do ensino de língua estrangeira. A experiencia de outros países nos mostra que a área de conhecimento língua estrangeira deve ser reconhecida e receber tratamento adequado: carga didática que favoreça a aprendizagem de um ou mais códigos linguísticos em sua totalidade, material didático compatível, profissionais devidamente preparados e o reconhecimento por todos, Governo e cidadãos, de que uma visão formativa contribuirá para a formação de um cidadão crítico e capaz de ser sujeito de sua própria história em sua língua materna e, se for necessário, em uma língua estrangeira. O professor de línguas estrangeiras é quem deve deixar de aceitar passivamente as tendencias históricamente impostas, questioná-las e buscar uma identidade para o ensino de língua estrangeira na escola brasileira.

Palavras-chave: Língua estrangeira; Leitura; Política linguística.

Resumen: La enseñanza de la habilidad de lectura en la escuela no resolvió el problema del fracaso escolar de la enseñanza de lengua extranjera. La experiencia de otros paises nos muestra que el área de conocimiento lengua extranjera debe reconocerse y recibir tratamiento adecuado: carga didáctica que favorezca el aprendizaje de uno o más códigos lingüísticos en su integridad, material didáctico compatible, profesionales debidamente preparados y el reconocimiento por todos, Gobierno y ciudadanos, de que una visión formativa contribuirá a la formación de un ciudadano crítico y capaz de ser sujeto de su propia historia en su lengua materna y, si hace falta, en una lengua extranjera. El profesor de lenguas extranjeras es quien debe dejar de aceptar pasivamente las tendencias

* Doutora em Linguística. Professora Adjunta de Língua Espanhola da Universidade Federal do Rio de Janeiro. Contato: m.sebold@yahoo.com.br. 
históricamente impuestas, cuestionarlas y buscar una identidad para la enseñanza de lengua extranjera en la escuela brasileña.

Palabras-clave: Lengua extranjera; Lectura; Política lingüística.

\section{Introdução}

Neste texto nos propomos a discutir de maneira mais abrangente o tratamento que vem recebendo a língua estrangeira (doravante LE) no âmbito escolar nos últimos 40 anos, bem como a repercussão das ações políticas que norteiam atualmente o ensino de língua estrangeira no Brasil. A partir da discussão destas questões, propomos que o professor de língua estrangeira reveja as tendências impostas historicamente e construa uma identidade para o ensino de língua estrangeira na escola brasileira que considere nossa diversidade linguística e cultural visando à educação de um cidadão crítico e sujeito de sua própria história.

\section{A tradição de ensino de língua estrangeira}

Começamos situando historicamente o lugar da habilidade de compreensão escrita no contexto das metodologias de ensinoaprendizagem de Língua Estrangeira (LE). O ensino de línguas estrangeiras apresenta ainda hoje uma forte influência do ensino das Línguas Clássicas. Uma das primeiras tendências metodológicas no ensino de língua estrangeira foi o Método de Tradução, aquele utilizado para o ensino do latim e do grego. Essa metodologia, que ainda hoje é utilizada no ensino do latim e do grego, caracterizava-se pela leitura de textos de autores consagrados para posterior tradução. A leitura era, pois, exercitada, mas não com vistas ao significado, isto é, não se exploravam as ideias do texto. Era simplesmente um meio para se adquirir as estruturas da língua.

Em outro momento, a leitura também serviu de meio para desenvolver a oralidade. Assim, no Método Áudio-Oral, nos níveis mais avançados, os textos literários apareciam como pretexto para a produção oral, sem qualquer preocupação com a estrutura dos mesmos. 
Somente a partir da metodologia comunicativa é que a leitura passa a ocupar um lugar de destaque nos materiais para ensino de língua estrangeira, isto é, os textos não aparecem exclusivamente como fonte de insumo linguístico para uma atividade de interação oral. Mas ainda é vista como uma habilidade secundária a ser desenvolvida junto com as outras três que compõem o inventário de uma língua estrangeira: compreensão oral e escrita, produção oral e escrita.

Na minha experiência pessoal como aluna de escola pública, há dois momentos significativos a relatar que interessam a minha linha de argumentação. O primeiro no então primeiro grau, quando na $5^{a}$ série (atual $6^{\circ}$ ano do ensino fundamental) recebemos a visita de um curso livre de inglês que distribuiu bolsas de seis meses de duração. A justificativa para estudar a língua estrangeira fora da escola já era então que na escola não se aprendia uma língua estrangeira. No Ensino Médio, também numa escola pública, aprendi uma segunda língua estrangeira, o francês, em três anos e me transformei numa proficiente falante da língua.

Historicamente era possível aprender uma língua estrangeira na escola. Na verdade, as línguas estrangeiras eram conteúdos importantes e tão ou mais valorizados que as demais disciplinas. No entanto, em algum momento começou-se a veicular a ideia de que a escola não reunia as condições necessárias a uma efetiva aprendizagem de uma língua estrangeira. A tarefa foi, então, naturalmente, delegada aos cursos livres que, curiosamente, tampouco dão conta da tarefa. Estabelecida esta primeira tendência, lançou-se outra: o ensino de uma única habilidade, a de leitura.

Cabe agora, portanto, fazer a seguinte pergunta: qual é o lugar para se aprender uma língua estrangeira? Lanço esta questão pensando não só nas escolas públicas e particulares onde há muitos relatos de professores e ex-alunos que afirmam haver estudado uma língua estrangeira por 11 anos e terem saído sem nenhum tipo de proficiência. Não sei se minha experiência como aluna de escola pública que saiu proficiente em uma língua estrangeira foi um caso único (não creio que tenha sido), mas a experiência de professora universitária de um curso de letras confirma um grande número de alunos egressos do ensino médio sem um mínimo de proficiência. Mas também pensando nos cursos livres de grande duração que tampouco garantem fluência 
aos seus usuários. Diante desse panorama de total ineficiência e falta de funcionalidade da língua estrangeira, cabe agora analisar algumas ações políticas.

\section{Ações políticas voltadas para o ensino de língua estrangeira no contexto escolar}

O panorama anteriormente apresentado revelava um fracasso histórico da língua estrangeira no contexto escolar. As primeiras ações políticas visavam inicialmente a justificar o que até então não se justificava: a importância de se aprender uma língua estrangeira na formação de um cidadão. $\mathrm{O}$ problema, entretanto, não estava no porquê mas no como. A finalidade sempre foi clara, mas os meios para alcançá-la foram definidos equivocadamente.

A área de ensino de línguas estrangeiras no Brasil se divide entre aqueles que postulam o ensino de língua estrangeira (LE) voltado para as quatro habilidades e aqueles que garantem que a realidade educacional brasileira só viabilizaria o ensino de qualidade de uma língua estrangeira se estivesse voltado unicamente para a habilidade de leitura. Os teóricos da área têm certamente suas razões para adotar uma ou outra postura. Mas muitos professores que têm a tarefa de implementar tais escolhas desconhecem tais razões.

A diversidade de contextos no Brasil traz realidades diferenciadas com necessidades específicas. Escolas técnicas têm uma demanda de língua instrumental mas escolas situadas em centros urbanos com potencial turístico ou escolas em cidades de fronteira têm uma demanda diferenciada que poderia priorizar o ensino de LE voltado para o desenvolvimento das quatro habilidades linguísticas.

Cabe, portanto, neste momento me reportar a duas ações políticas. Trata-se de dois documentos que passaram a orientar o ensino de língua estrangeira na escola: Os Parâmetros Curriculares Nacionais (PCN) e as Orientações Curriculares do Ensino Médio (OCM). Não será, entretanto, meu objetivo descrever ou analisar os dois documentos que já foram assunto de vários artigos e publicações. Meu objetivo é sim orientar uma leitura do que esses documentos representam em termos de uma política linguística. E a proposta deste artigo é fazer uma leitura de algumas dessas políticas e propor que haja sim políticas 
linguísticas no que diz respeito ao ensino de espanhol como língua estrangeira (LE), mas que integrem o professor como elemento que pode e deve contribuir porque ele melhor que qualquer um de nós conhece sua realidade e suas necessidades.

Para tratar do tema das políticas e planejamento da linguagem, Hamel (1993) introduz seu artigo com uma parábola:

Era uma vez um ancião muito solitário que vivia numa cabana no fundo da praia. Para distrair-se, começou de repente a trocar os nomes das coisas que o rodeavam. Chamou de mesa a cadeira; de banco a mesa; de chão a parede e de porta a janela. Depois de algum tempo esqueceu-se dos nomes originais das coisas, e quando se comunicava com alguém do povoado, o que acontecia muito raramente, as pessoas já não o entendiam, e isso aumentava então seu isolamento. ${ }^{1}$

Hamel trata a atitude do ancião como uma política linguística extrema com consequências desastrosas que revela um aspecto fundamental de toda política linguística: a possibilidade de intervir sobre a linguagem é determinada por relações de poder estabelecidas entre atores e grupos sociais. No nosso caso, também pode ter acontecido o mesmo. Políticas linguísticas extremas podem gerar uma situação desastrosa como a que vivemos no ensino de LE no Brasil no contexto escolar.

E neste argumento pode-se centrar a extensão de uma política linguística que, por um lado oferece em alguma medida algum poder àquele que estuda uma língua estrangeira na escola, porque lhe dá uma proficiência linguística (ainda que seja em uma única habilidade

${ }^{1}$ No original: Érase una vez un anciano muy solitario que habitaba una cabaña al fondo de la playa. Para entretenerse, empezó un día a cambiarle los nombres a las cosas que lo rodeaban. Llamó mesa a la silla; a la mesa banco; a la pared suelo y a la ventana puerta. Al cabo de un tiempo se le olvidaron los nombres originales de las cosas, y cuando se comunicaba con alguien del pueblo, lo que rara vez sucedía, la gente ya no le entendía, de modo que aumentaba su aislamiento. 
linguística), o que antes sequer se conseguia. Essa política linguística que gerou os Parâmetros Curriculares Nacionais definiu prioritariamente o ensino da habilidade de leitura como solução mais eficaz para um problema bem maior: o fracasso do ensino na escola.

O Projeto Nacional de Inglês Instrumental em Universidades Brasileiras foi introduzido no Brasil na década de 70. Este projeto foi muito importante por ter introduzido a metodologia de ensino de leitura e ter dado uma nova dimensão à habilidade de leitura, antes vista somente como reconhecimento da representação gráfica de sons e trabalhada através de perguntas e respostas em busca de uma reconstrução do texto via uma leitura subjetiva do professor e as publicações e cursos gerados a partir dele contribuíram para o efetivo papel do leitor na construção do sentido e, consequentemente, viabilizaram a formação de um leitor crítico.

Entretanto, o objetivo que inicialmente era a leitura acadêmica e visava a atender tão somente aos alunos universitários da graduação e da pós-graduação, acabou por se estender também ao ensino médio e fundamental.

No Brasil, então, por influência desse projeto, a habilidade de leitura passou a ser desenvolvida como uma habilidade especifica em contextos também específicos. Os Parâmetros Curriculares Nacionais esclarecem que o desenvolvimento das habilidades orais no ensino de Língua Estrangeira no Brasil não atende às necessidades específicas e mais imediatas da população. Apresenta, ainda, como argumento os exames de seleção do Vestibular e os de ingresso aos cursos de pósgraduação, objetivos em longo prazo de uma parte dos estudantes, que estão organizados com vistas a checar as habilidades de leitura. Além do mais, o documento trata da total falta de condições (salas de aula cheias, falta de material adequado, etc.) que não favorece o ensino de língua estrangeira com qualidade.

Em outro contexto de produção, as OCEM (BRASIL, 2005a) têm o objetivo de retomar a reflexão sobre a função educacional do ensino de LE no ensino médio destacando a importância desta área de conhecimento a fim de que o ensino-aprendizagem de uma língua estrangeira também contribua para a formação crítica de indivíduos.

Assim, o valor educacional da aprendizagem de uma língua estrangeira vai muito além de meramente capacitar o aluno a usar uma 
determinada língua apenas para se comunicar. Esse ensino-aprendizagem envolve questões de inclusão-exclusão, formação de identidade, conceito de cidadania, etc. $\mathrm{O}$ documento esclarece com relação às habilidades a serem desenvolvidas no ensino de LE no Ensino que "focaliza a leitura, a prática escrita e a comunicação oral contextualizadas" (BRASIL, 2005a, p. 87). Ao propor o ensino da língua estrangeira voltado para as quatro habilidades linguísticas, a política linguística amplia a extensão de poder daquele que estuda uma língua estrangeira na escola.

Considerando-se o segundo ciclo do Ensino Fundamental $\left(6^{\circ}\right.$ ano ao $9^{\circ}$ ano): 4 anos e o Ensino Médio: 3 anos, temos um total de 7 anos. Esse período de tempo em termos de uma LE é significativo para uma efetiva aprendizagem. Os problemas apresentados como justificativa para o ensino da habilidade de leitura nos PCN, tais como: falta de infra-estrutura, número excessivo de alunos em sala de aula, entre outros são antigos e se mantêm também no Ensino Médio. E se mantêm porque não são específicos da disciplina língua estrangeira. $\mathrm{O}$ ensino de uma maneira geral passa por um momento de crise não só na escola pública. Respiramos tecnologia e modernidade, mas a escola continua presa a uma tradição desmotivadora.

Para avaliarmos a situação de ensino-aprendizagem da LE no contexto da escola brasileira buscamos conhecer a experiência de outros países no tratamento desta área de conhecimento.

\section{Olhando para fora de nós mesmos}

É fato inegável que a política linguística no Brasil tem gerado algumas ações importantes para a melhoria do ensino-aprendizagem da LE no âmbito escolar. Não só os documentos de referência elaborados (os PCN e as OCEM), mas também a avaliação de material dedicado ao ensino-aprendizagem : dicionários e gramáticas e ainda o Programa Nacional do Livro Didático (PNLD) agora extensivo à LE. Mas vemos que entre cada uma dessas conquistas há um distanciamento muito grande e que, talvez, precisássemos mais de um grande pacote de ações integradas. Mas esse, de fato, não é só um problema nosso. Como outros países enfrentam o mesmo problema? A experiência de outros pode melhor nossa visão sobre o assunto. 
As informações sobre as políticas linguísticas de outros países aparecem esparsamente em alguns artigos ou em notícias. Interessa em particular o tratamento que a LE recebe na escola e a sua repercussão na formação de um cidadão.

Minha primeira tentativa voltou-se para a Europa. A primeira referência foi uma notícia de novembro de 2008 de título bem sugestivo: "Alunos da EU aprendem línguas estrangeiras cada vez mais cedo." 2 A notícia faz menção a um estudo da Comissão Europeia e destaca como pontos principais o apoio crescente à aprendizagem de línguas e o reforço da aprendizagem de LE cada vez mais cedo. Igualmente reveladora é a menção do Comissário Europeu de alcançar o objetivo de que todos os alunos tenham a possibilidade de aprender duas línguas estrangeiras na escola. Tal objetivo foi estabelecido em Barcelona no ano de 2002 e constitui uma das oito competências essenciais da aprendizagem ao longo da vida recomendadas pelo Conselho e pelo Parlamento Europeu em 2006.

Os dados apresentados são relativos ao ano letivo de 2006/ 2007 e revelam a realidade das escolas públicas e particulares. As conclusões do estudo são particularmente significativas. Informa que o ensino de LE começa mais cedo embora apresente uma carga letiva mais reduzida no primeiro ciclo do ensino básico e que a obrigatoriedade do ensino da LE se expandiu a quase todos os países da Europa.

Em algumas comunidades autônomas da Espanha e na Bélgica, as crianças começam a aprendizagem de uma língua estrangeira aos 3 anos de idade. No primeiro ciclo do ensino básico, o tempo dedicado à aprendizagem é inferior a $10 \%$ da carga didática total. Destaca ainda que se por um lado, o ensino de, pelo menos, duas línguas estrangeira desde cedo ainda não é realidade em todos os países, no que diz respeito aos cursos gerais do ensino secundário na maioria dos países, o oferecimento de duas línguas estrangeiras é, sim, uma realidade.

O panorama oferecido contrasta em muitos aspectos com o nosso. Primeiro, pelo reconhecimento do valor formativo da área de

2 Notícia disponível em: <http://europa.eu/rapid/pressReleasesActiondo/ reference>. Acesso em: 23 fev. 2010. 
conhecimento língua estrangeira na escolarização. Também chama a atenção a meta de que o aluno aprenda pelo menos duas línguas estrangeiras na escola. Entretanto, o texto não esclarece o que se entende por "aprender" uma língua estrangeira.

Em notícia menos recente ${ }^{3}$ com o título de "Mais de 40 países celebram o ano Europeu das Línguas", encontramos informações importantes sobre o ensino de LE em alguns países da Europa. A meta para tais países é "celebrar a diversidade lingüística" e "incentivar a aprendizagem de línguas estrangeiras". A notícia denuncia que na Europa menos da metade dos cidadãos são capazes de falar pelo menos um idioma.

A notícia faz referência ao Livro Branco da Comissão Europeia "Rumo à sociedade cognitiva" que já no ano de 1995 definia como objetivo " que no final da escolaridade, todos os cidadãos fossem capazes de falar pelo menos duas línguas estrangeiras para além da materna". Entretanto, dados do ano 2000 revelavam que 47,3\% dos cidadãos da comunidade só falavam sua língua materna.

Significativa também é a menção ao estudo da Comissão Europeia "Aprendizagem de línguas estrangeiras nas escolas da Europa" que trazia uma avaliação dos diferentes sistemas de ensino e da sua evolução. Este estudo analisou 29 países. Na maioria desses países se começa a aprender uma LE entre os oito e os onze anos. Luxemburgo, Noruega e Áustria começam mais cedo, aos seis anos. Luxemburgo tinha a menor porcentagem de cidadãos que afirmava só dominar a língua materna: $2,2 \%$. O texto destaca como importante o fato de que neste país, mais de $50 \%$ do horário escolar seja preenchido com as línguas na faixa dos dez aos treze anos, período cientificamente comprovado como produtivo para a aprendizagem de uma língua estrangeira.

Entretanto, no que diz respeito ao papel dado à aprendizagem de mais de um idioma, somente metade dos países da EU (União Europeia) incluíam duas línguas estrangeiras obrigatórias no currículo.

\footnotetext{
${ }^{3}$ Data de 5 de março de 2001. Disponível em: <http://www2.fcsh.unl.pt/ act2001/publico-5-3-2001.htm>. Acesso em: 23 fev. 2010.
} 
Esta última notícia reforça a informação de que na Europa as políticas linguísticas aconselham o ensino-aprendizagem de duas línguas estrangeiras durante a escolaridade e de que o processo está orientado para o desenvolvimento das quatro habilidades linguísticas (quando se utiliza da expressão "falar uma língua estrangeira”) já que não há qualquer referência a uma habilidade linguística em separado.

A terceira e última notícia recolhida tem data de 2007 e como título: "Objectivos da UE para o ensino de línguas estrangeiras vão marcar passo em Portugal”. ${ }^{4}$ Segundo a notícia, embora no encontro realizado em Barcelona no ano de 2002 os chefes de Estado e de Governo tivessem assumido como compromisso "proporcionar "a todos" o ensino de, "pelo menos, duas línguas estrangeiras, a partir de uma idade muito precoce", Portugal em 2007 continuava em atraso no cumprimento dessa meta.

O texto menciona ainda que a EU quer ir além do multilinguismo. Pretende que os cidadãos sejam poliglotas, isto é, com pelo menos a língua materna e duas línguas estrangeiras. $\mathrm{O}$ argumento de uma professora de inglês premiada pelo Ministério da Educação é revelador: "Uma língua estrangeira é um espaço privilegiado para promover a interculturalidade e para preparar os alunos para o exercício da cidadania".

A crítica ao caráter extracurricular dado ao ensino do Inglês no primeiro ciclo que faz com que a frequência não seja obrigatória e a LE tenha menor peso no currículo também é inspiradora.

O plano de ação da EU proposto em prol da diversidade linguística para o biênio 2004-2006 destacava que a aprendizagem precoce das línguas só seria significativa se os professores tivessem sido formados especificamente para ensinarem línguas a crianças pequenas, se as turmas fossem reduzidas, se houvesse material didático adequado e se o tempo letivo fosse suficiente. O Eurobarômetro sobre competências linguísticas - "Os europeus e as suas línguas" realizado em dezembro de 2005, revelava que 65\% dos cidadãos da EU aprendeu na escola uma LE.

\footnotetext{
${ }^{4}$ Data de 25 de novembro de 2007. Disponível em: <http://www2.fcsh.unl.pt/ ilnova/Multilinguismo/ Objectivos_UE_ensino_LE.pdf $>$. Acesso em: 23 fev. 2010.
} 


\section{Voltando o olhar sobre nós mesmos}

Os dados obtidos nos permitem conhecer uma maneira diferente de conceber o ensino de língua estrangeira na escola e nos fazem repensar a política linguística de língua estrangeira no âmbito escolar no Brasil.

Trata-se de uma política voltada para a valorização da área de conhecimento de língua estrangeira. Tal valorização poder ser evidenciada pelo espaço ocupado pela disciplina na grade curricular (que pode chegar a até $50 \%$ do horário escolar como no caso de Luxemburgo). Colabora igualmente reforçando o papel formativo da língua estrangeira, a proposta de plurilinguismo.

No caso do Brasil, um olhar rápido sobre as leis já nos permite entender que no nosso caso a história é bem diferente. A Lei 5.692 de Diretrizes e Bases para o ensino de $1^{\circ}$ e $2^{\circ}$ graus, de 11 de agosto de 1971 (BRASIL, 1971), não faz referência ao ensino de língua estrangeira. Em 1996, na Lei de Diretrizes e Bases para a Educação Nacional 9394/96 (BRASIL, 1996), o inciso terceiro do Art. 36 fazia referência à inclusão de uma língua estrangeira moderna como disciplina obrigatória e uma segunda em caráter optativo. E, infelizmente, no caminho totalmente contrário às experiências de outros países, a Lei 11.161/2005 (BRASIL, 2005b) determinou como obrigatório o ensino de uma única LE também previamente determinada: o espanhol.

Se por um lado, esta lei gerou uma tarefa impossível de operacionalizar: como reunir um "exército" de professores de tal tamanho? Que receita ou mágica poderia solucionar um problema com o tamanho do Brasil? Por outro, nos afastou completamente do objetivo de plurilinguismo que a EU busca alcançar e parece muito mais coerente com a diversidade linguística e cultural de nosso país.

Nem é preciso detalhar todos os interesses que estão por detrás de uma lei que favorece exclusivamente uma única LE. Não ganhamos os professores de espanhol, não ganharam os professores das outras línguas, não ganharam os alunos, enfim, não ganhou a escola brasileira!

O modelo atual de fracasso do ensino de língua estrangeira na escola não foi resolvido com a redução do ensino a uma única habilidade linguística. A experiência de outros países nos mostra que a área de conhecimento língua estrangeira deve ser reconhecida e deve receber 
tratamento adequado: carga horária que favoreça a aprendizagem de um ou mais códigos linguísticos em sua integridade, material didático compatível, profissionais devidamente preparados e o reconhecimento por todos, Governo e cidadãos, de que uma visão formativa contribuirá para a formação de um cidadão crítico e capaz de ser sujeito de sua própria história em sua língua materna e, se necessário, em uma língua estrangeira. Cabe a nós professores de língua estrangeira deixar de aceitar passivamente as tendências historicamente impostas, questionálas e buscar uma identidade para o ensino de língua estrangeira na escola do Brasil.

\section{Referências}

BRASIL. Lei no 5.692, de 11 de agosto de 1971. Fixa Diretrizes e Bases para o ensino de $1^{\circ}$ e $2^{\circ}$ graus, e dá outras providências. Diário Oficial da União, Brasília-DF , 12 ago. 1971.

. Lei n ${ }^{\circ}$ 9.394, de 20 de dezembro de 1996. Estabelece as diretrizes e bases da educação nacional. Diário Oficial da União, Brasília-DF, 23 dez. 1996. Disponível em: < http://portal.mec.gov.br/ arquivos/pdf/ldb.pdf>. Acesso em: 23 fev. 2010.

. Parâmetros Curriculares Nacionais. Ensino Médio. Brasília: MEC, 1999.

Orientações curriculares para o ensino médio. Linguagens, códigos e suas tecnologias. Brasília: MEC, 2005 a.

BRASIL. Lei $\mathrm{n}^{\circ}$ 11.161, de 5 de agosto de 2005. Dispõe sobre o ensino de língua espanhola. Diário Oficial da União, Brasília-DF, 8 ago. 2005 b.

HAMEL, R. E. Políticas y planificación del lenguaje: una introducción. Iztapalapa (Políticas de lenguaje en América Latina), n. 29, p. 5-39, 1993. 